\title{
Effect of Pulp Properties on the Power Consumption in Low Consistency Refining ${ }^{1}$
}

\author{
Huan LIU@ $\mathbb{C}^{2,3, \dagger} \cdot$ Jixian DONG $\mathbb{D}^{2,3, \dagger} \cdot \mathrm{Kai}^{2,3} \cdot$ Xiya $\mathrm{GUO}^{2,3} \cdot$ Ying YAN ${ }^{4} \cdot$ \\ Lijie $\mathrm{QIAO}^{2,3} \cdot$ Chuanwu DUAN ${ }^{2,3} \cdot$ Zhiming $\mathrm{ZHAO}^{2,3}$
}

\begin{abstract}
The power consumption in the low consistency (LC) refining is an important indicator for the optimal control of the process and it is composed of the net power and the no-load power. The refining efficiency and process characterization of LC refining are directly affected by power consumption. In this paper, the effect of pulp consistency and average fiber length on the power consumption and refining efficiency were studied through the LC refining trials conducted by an experimental disc refiner. It is found that the curve of power-gap clearance can be divided into constant power section, power reduction section, and power increase section. And the no-load power and the adjustable domain of loading applied by the refining plates will increase as the increase of pulp consistency, while the increase of net power is larger than that of no-load power which makes the increasing of refining efficiency. Meanwhile, the adjustable domain of loading applied by the refining plates can be slightly improved by increasing the average fiber length, but its effect on the no-load power in the LC refining process can be neglected. The study of power consumption in LC refining is of positive significance for the proper selection of pulp properties in LC refining, in-depth exploration of refining mechanism, and energy consumption reduction in refining.
\end{abstract}

Keywords: low consistency refining, pulp consistency, average fiber length, no-load power, refining efficiency

\section{INTRODUCTION}

The low consistency (LC) refining is an important operating unit for the modification of the properties of pulp and fibers. Disc refiner is the widely used equipment for pulp refining, and the raw materials werefed into the rotating refining zone composed of rotor and stator. Meanwhile, it would undergo complex forces, such as normal force, shear force, and corner force (Gharehkhania et al., 2015), applied by the plates with a special bar profile, for the adjustment of the structure and properties. During the normal refining process, the mechanical energy was transmitted from the main shaft to the refining zone and then com-

${ }^{1}$ Date Received July 14, 2020, Date Accepted October 29, 2020

${ }^{2}$ College of Mechanical and Electrical Engineering, Shaanxi University of Science \& Technology, Xi'an, Shaanxi Province, 710021, People's Republic of China

${ }^{3}$ China Key Laboratory of Light Industry Equipment Manufacturing Intelligence, Xi'an, Shaanxi Province, 710021, People's Republic of China

${ }^{4}$ Henan Cigarette Industry Sheet Co., Ltd., Xuchang, Henan Province, 461100, People's Republic of China

$\dagger$ Corresponding author: Huan LIU (e-mail: liuhsust@126.com, ORCID: 0000-0001-5975-1624) and Jixian DONG (e-mail: djx@sust.edu.cn, ORCID: 0000-0002-2373-2525) 
Huan LIU $\cdot$ Jixian DONG $\cdot$ Kai QI $\cdot$ Xiya GUO $\cdot$ Ying YAN $\cdot$ Lijie QIAO $\cdot$ Chuanwu DUAN $\cdot$ Zhiming ZHAO

pletely converted into fiber modification energy and heat (Lundin et al., 2009). The power consumption in LC pulp refining is composed of the no-load power, maintaining the normal operation of disc refiner with pulp, and the net power used for the fiber modification.

LC refining process is usually characterized by the refining intensity, such as specific edge load (SEL) (Wultsch and Flucher, 1958), specific surface load (SSL) (Lumiainen 1990), net normal force or tangential force per crossing point (Roux et al., 2009), etc. Most of them are calculated based on the net power, obtained by subtracting the no-load power from the total power (Jorge et al., 2019), which indicates the accurate measurement of the net power is important for the precise control of the LC refining. So the detection of the net power can be transformed into the measurement of the no-load power and total power. Meanwhile, the optimal control of refining efficiency and quality of LC refining can be obtained by reducing the no-load power. The no-load power of LC refining is approximately in the range of $20 \%$ to $50 \%$ of the total power (Lumiainen, 1994), related to the types of the refining equipment, plate size, and other parameters. The definition, calculation, and measurement methods of the no-load power can be obtained in the previous studies (Liu et al., 2020).

Plate size, rotation speed, the pulp properties, and bar parameters of refining plates are the main factors that affect the power consumption during LC refining. The no-load power of disc refiner in LC refining increase with the increasing of the plate diameter (Rajabi Nasab et al., 2013; Banks, 1967), and the net power is proportional to the rotation speed of the plates, while the no-load power is proportional to the cube of it (Ragnar, 1970). The pulp properties, such as pulp consistency, pulp type, etc., would affect the power consumption and the impact performance on pulp in the LC refining. The no-load power of disc refiner fill- ing with water and other pulps was compared previously (Lundin, 2008; Luukkonen, 2011; Bordin et al., 2008), however, few studies exploring the effect of the fiber length and pulp consistency on power consumption and refining efficiency was found.

The objective of this study is to explore the effect of pulp properties, such as pulp consistency and average fiber length, on the refining efficiency and power consumption in LC refining. Water and three types of pulp with different pulp consistency were used to fill the refining zone for the power consumption study. And the no-load power, power consumption, and refining efficiency of different trials were analyzed.

\section{MATERIALS and METHODS}

\subsection{Raw materials}

In the refining trials, bleached sulphate eucalyptus pulpboard (HW), unbleached kraft pulpboard (SW), and water were used as the raw material. And the experimental materials were made by mixing two types of board, hardwood and softwood pulp, in different ratios, as shown in Table 1 . Besides, the beating degree of unbleached kraft pulp is $13^{\circ} \mathrm{SR}$. After that, the mixed pulp board was soaked in distilled water for $2 \mathrm{~h}$ and then dissipated by a pulp disintegrator PD10 (Techlab Systems, San Sebastian, Spain), and its consistency was adjusted to $1 \%, 2 \%$, and $3 \%$.

\subsection{Experimental methods}

\subsubsection{MD3000 single-disc refiner}

The LC refining trials were performed through a MD3000 single-disc experimental refiner (Regmed, Osasco, Brazil), as shown in Fig. 1. During LC refining, the pulp flow rate is in the range of $4.3 \sim 4.6 \mathrm{~m}^{3} / \mathrm{h}$ and the temperature of the pulp used in the trials is $20^{\circ} \mathrm{C}$. All trials were conducted using an isometric straight bar plate (Fig. 2), directly processed by Nantong 
Effect of Pulp Properties on the Power Consumption in Low Consistency Refining

Table 1. The trials' code and the pulp properties used in this study

\begin{tabular}{|c|c|c|c|c|c|}
\hline $\begin{array}{c}\text { Trials' } \\
\text { code } \\
\end{array}$ & Pulp type & Mixed ratio & $\begin{array}{c}\text { Length-weighted average } \\
\text { fiber length } \\
\end{array}$ & Beating degree & Pulp consistency \\
\hline 1 & water & 1 & 1 & 1 & 1 \\
\hline 2 & & & & & $1 \%$ \\
\hline 3 & HW & $100 \%$ & $0.92 \mathrm{~mm}$ & $12^{\circ} \mathrm{SR}$ & $2 \%$ \\
\hline 4 & & & & & $3 \%$ \\
\hline 5 & & & & & $1 \%$ \\
\hline 6 & HW : SW & $4: 1$ & $1.22 \mathrm{~mm}$ & $13^{\circ} \mathrm{SR}$ & $2 \%$ \\
\hline 7 & & & & & $3 \%$ \\
\hline 8 & & & & & $1 \%$ \\
\hline 9 & HW : SW & $3: 2$ & $1.52 \mathrm{~mm}$ & $13^{\circ} \mathrm{SR}$ & $2 \%$ \\
\hline 10 & & & & & $3 \%$ \\
\hline
\end{tabular}

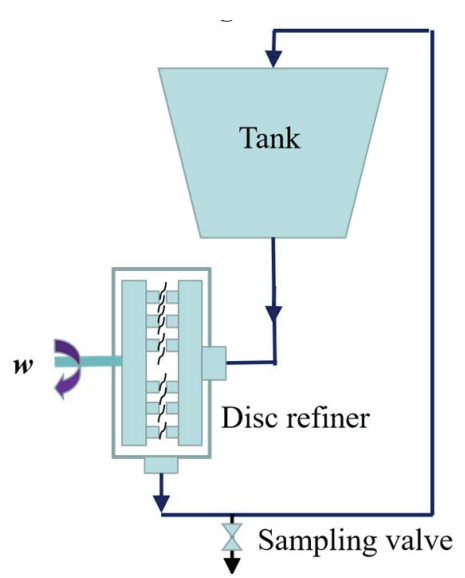

Fig. 1. MD3000 single-disc experimental refiner.

Huayan Casting Co., Ltd. (Nantong, China) through the computer numerical control (CNC) machine tools (X6132; Shenzhen Dima Co., Ltd., Shenzhen, China) at a constant speed $(1460 \mathrm{rpm})$.

\subsubsection{Data collection}

During the LC refining, the data of power consumption was collected by adjusting gap clearance in the range of $0 \mathrm{~mm}$ to $5 \mathrm{~mm}$. And the no-load power should be measured by its definition, actually, two general definitions of no-load power in LC refining

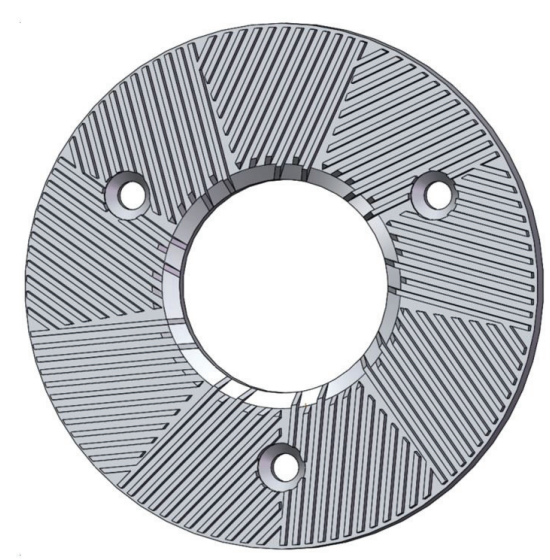

Fig. 2. Isometric straight bar plate"2-3-4-5".

existed (Liu et al., 2020). While the first one refers to the power consumption which isn't used for fiber modification, and it can be measured by the critical power when the gap clearance is fixed at a critical value. And another refers to the minimum energy consumption required to run the refiner filling of pulp. According to the first definition, the no-load power can be measured by the power at the critical gap (Roux, 2001), but it is difficult to determine the precise value of a critical gap. For another, the no-load power can be measured by adjusting the gap clearance 
sufficient large, usually larger than $2.5 \mathrm{~mm}$, when the refining zone is filled with pulp (Rajabi Nasab et al., 2013), and it was concerned in this study.

\section{RESULTS and DISCUSSION}

\subsection{Power consumption-gap clearance curve}

The power consumption of the refining process filled with water and different pulps under different gap clearances were explored in this study. And it was found three sections of constant power, power reduction, and power increase section existed when the gap clearance was adjusted in the range of $0 \mathrm{~mm}$ to $5 \mathrm{~mm}$ during refining, as shown in Fig. 3, which is basically consistent with the conclusion of the previous study, as shown in Fig. 4 (Bordin et al., 2008).

The power constant section refers to the region of constant power consumption of LC refining when the gap clearance is larger than $2 \mathrm{~mm}$. The power in that section is almost maintained constant due to the small fluctuations of the load under the condition of large gap clearance. While the section on power reduction, refers to the refining process with gap clearance in the range of $0.5 \mathrm{~mm}$ to $2 \mathrm{~mm}$, the power consumption

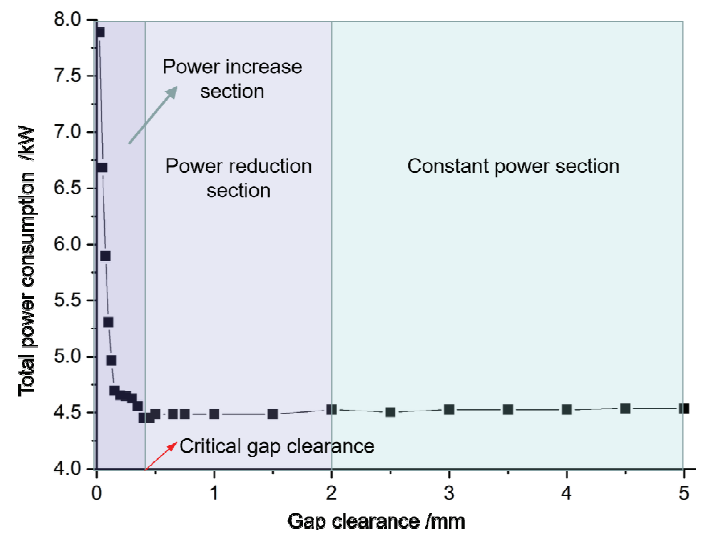

Fig. 3. The relationship between the total power and gap clearance in disc refiner filling with water.

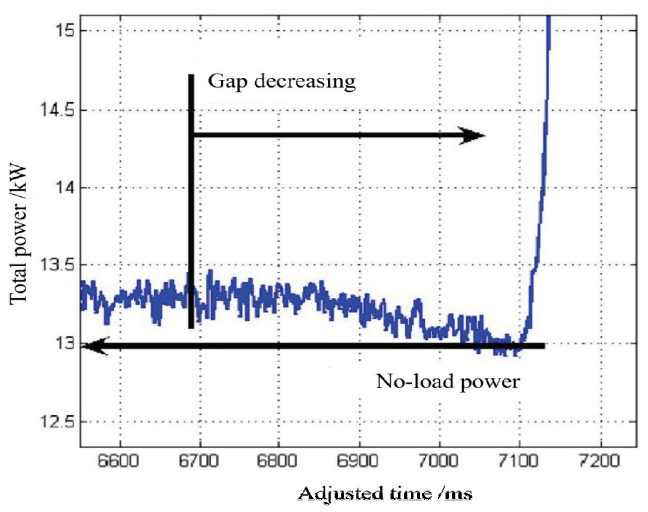

Fig. 4. The size of no-load power while gap decreasing (Bordin et al., 2008).

decrease with the decreasing of gap due to that the power change is sensitive to the amount of pulp in the refining zone compared to that of the constant power section. Both the constant power and the power reduction section are the no-load stage for a relatively small change of power consumption. However, in the power increase section, the mechanical force applied by plates directly act on the pulp when the gap is less than the critical gap clearance. Therefore, the friction between the bar and fibers increases sharply with the reduction of the gap clearance, and most of the energy in this section was used for the modification of fiber properties. The effective refining in LC refining should be conducted in the power increase section according to the requirements of the pulp properties.

\subsection{Power consumption and pulp consistency}

Pulp consistency is one of the key parameters of the raw pulp in pulp refining, and it is generally in the range of $2 \%$ to $6 \%$ during the $\mathrm{LC}$ refining process (Roux, 2001). In this paper, three mixed pulps were used to explore the effect of pulp consistency on the power consumption in LC refining, as shown in Fig. 5. Through analyzing the power consumption of the 


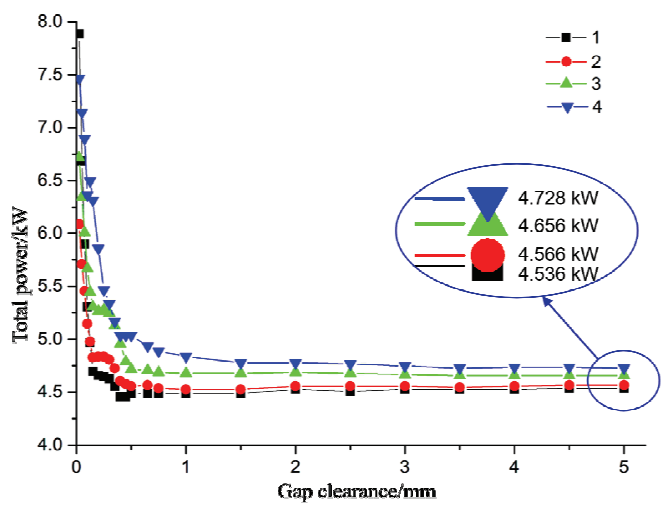

(a) Hardwood pulp and water

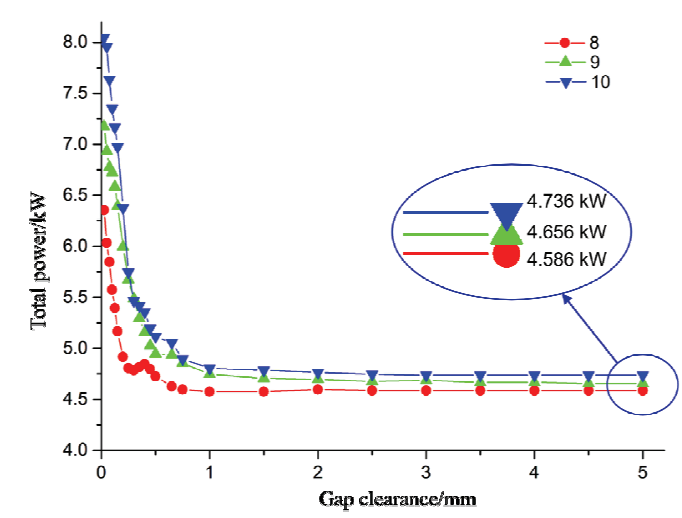

(c) Mixed pulp at ratio of 2:3

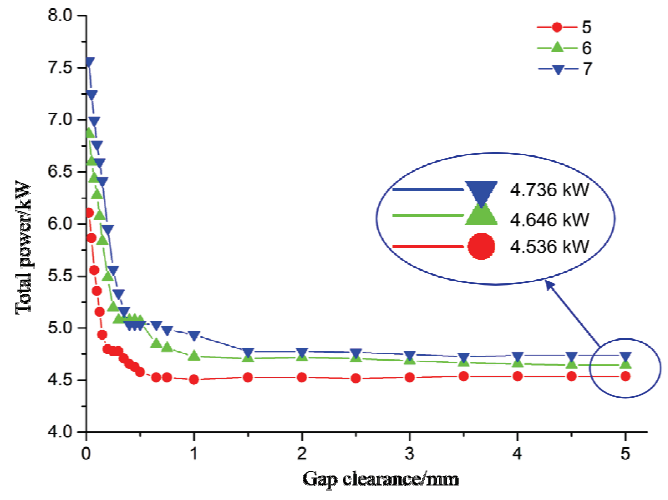

(b) Mixed pulp at ratio of $1: 4$

Fig. 5. Effect of pulp consistency on the power consumption in LC refining.

constant power section in different refining processes, it can be found the no-load power of the LC refining process increases with the increase of the pulp consistency. The mechanical loss power of the refining plate used in this study was measured by the idle rotation and it maintained $3.916 \mathrm{~kW}$. This means that the sum of pulp pumping and hydraulic loss power in LC refining increases with the increase of the pulp consistency.

The impact performance of plate on pulp can be characterized by the critical gap clearance and the power increase, related to the no-load power, during LC refining. As shown in Fig. 5(a), the critical gap clearance of LC refining gradually increases with the increase of the pulp consistency, which means that the loading ability of the refining plates can be improved through the increasing of pulp consistency. While the power increase reflects the domain of power adjustment in an efficient refining region during $\mathrm{LC}$ refining. As shown in Fig. 5(c), the power increase of trials 8,9 , and 10 are $1.77,2.52$, and $3.31 \mathrm{~kW}$, respectively, which means that the power increase, or the adjustable range of power consumption, is larger when the pulp was refined in a higher consistency. However, the power increase of refining filled with water is 3.35 $\mathrm{kW}$, which is greater than the power increase of all other trials. The water has better fluidity and it is difficult to carry large loads, therefore, the direct friction 


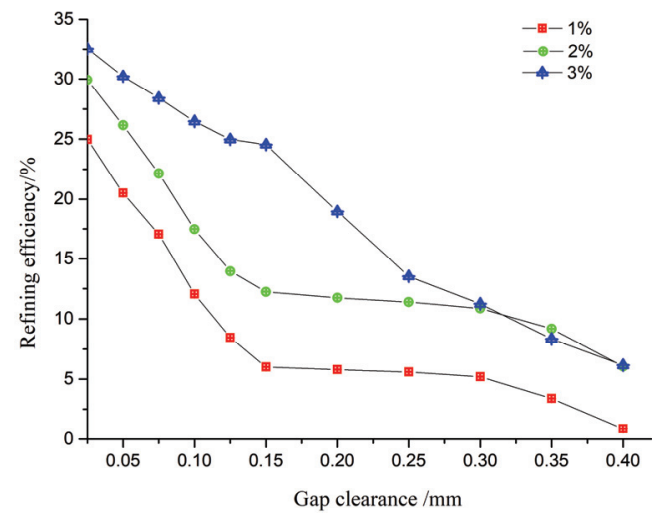

Fig. 6. Effect of pulp consistency on the refining efficiency of hardwood pulp refining.

between the rotor bars and stator bars was produced due to the poor withstand load ability of water.

The refining efficiency, described by the ratio of net power and total power, is a key indicator to measure the energy consumption in LC refining, however, it was less concerned with actual refining. The refining efficiency of industrial refiners is generally higher than $75 \%$, while that of experimental disc refiners is relatively lower, generally in the range of $35 \%$ to $50 \%$ (Bordin et al., 2008). In this paper, the refining efficiency of trials 2, 3, and 4 was analyzed when the gap clearance is in the range of 0 to $0.4 \mathrm{~mm}$, as shown in Fig. 6, it is found that the refining efficiency of LC refining gradually increases as the plate gap clearance decreases. Meanwhile, the refining efficiency would be affected by the pulp consistency, the higher the pulp consistency, the higher the refining efficiency of LC refining, which is basically consistent with the conclusion obtained by the analysis of load capacity. While it is necessary to select the proper pulp consistency according to the actual process requirements.

\subsection{Power consumption and average fiber length}

The beating degree and wet weight of the pulp are the two important parameters to measure the pulp quality (He, 2010; Guo et al., 2020). The initial beating degree of pulp studied in this paper is basically the same, and three types of mixed pulp with different fiber lengths were used to explore the influence of the average fiber length on the power consumption and refining efficiency in the LC refining process. The effect of fiber length on refining efficiency seems to be greater compared to other fiber morphological parameters, such as fiber width, fiber thickness, fiber internal and external fibrillation, in the view of the experience. So some fiber morphological parameters, which strongly affect the paper and paper properties, were neglected in the exploration of power consumption and refining efficiency in this paper.

The average fiber length of pulp will directly affect the power consumption in the LC refining, as shown in Fig. 7. Through the analysis of the power consumption in the constant power section, it was found there is a slight effect of fiber length on no-load power when the pulp consistency is $1 \%$, but almost no effect on the others, as shown in Fig. 8. In addition, the power increase in the efficient refining region slightly increases with the increase of the average fiber length, which means the longer fiber pulp refining is beneficial to increase the load capacity of the refining plates in the LC refining process. As shown in Fig. 7(b), the power increase, related to the no-load power, for the refining process of three types of pulps with fiber lengths of $0.92,1.22$, and $1.52 \mathrm{~mm}$, are 2.06, 2.22, and $2.52 \mathrm{~kW}$, which is much less than the effect of the pulp consistency. Therefore, it is difficult to effectively adjust the impact ability of the disc refiner by increasing the average fiber length in the LC refining.

In this study, the refining efficiency of trials 4, 7, and 10 when the gap clearance is in the range of 0 to $0.5 \mathrm{~mm}$ were analyzed, as shown in Fig. 9. It was found that the refining efficiency of the LC refining process decreases with the increasing of the gap clearance, and it will be slightly higher when the pulp with 
Effect of Pulp Properties on the Power Consumption in Low Consistency Refining

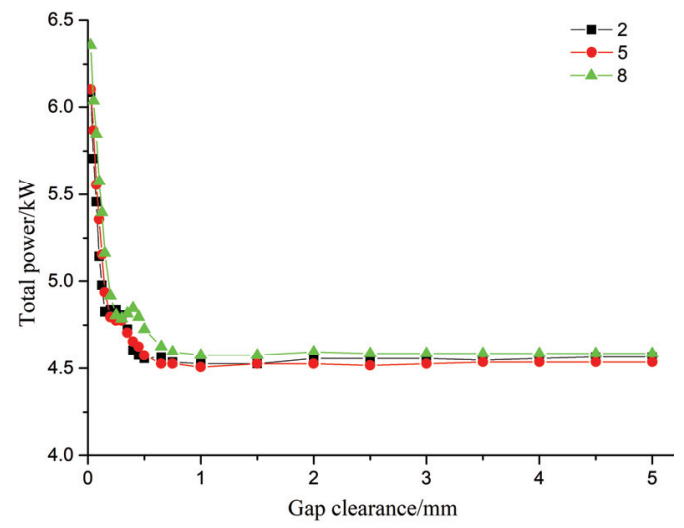

(a) Pulp consistency $1 \%$

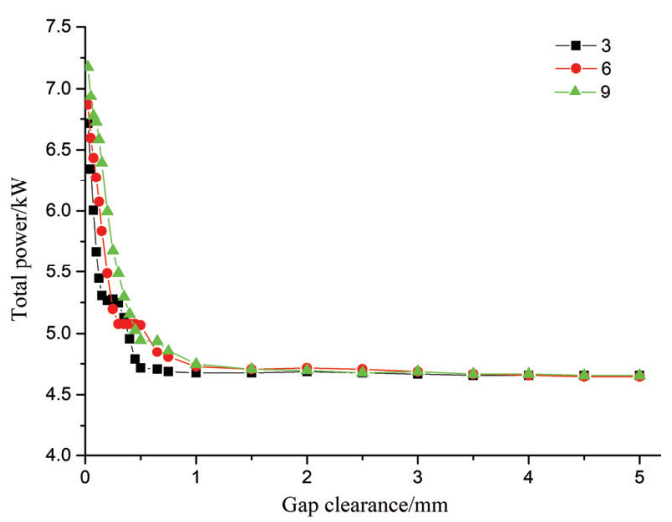

(b) Pulp consistency $2 \%$

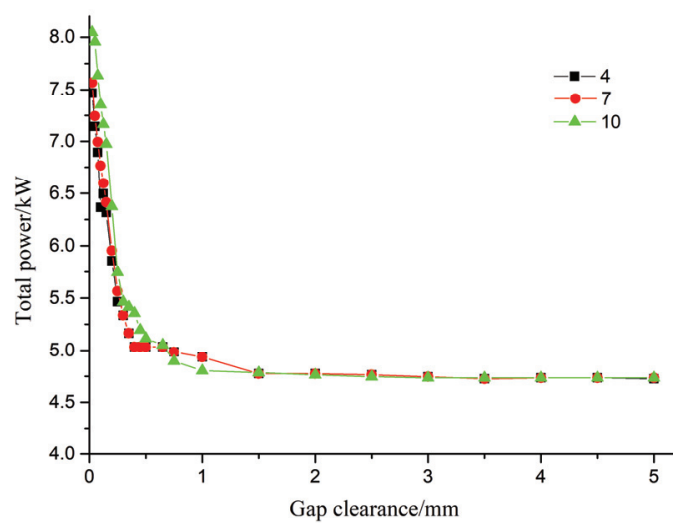

(c) Pulp consistency 3\%

Fig. 7. Effect of average fiber length on the power consumption in LC refining.

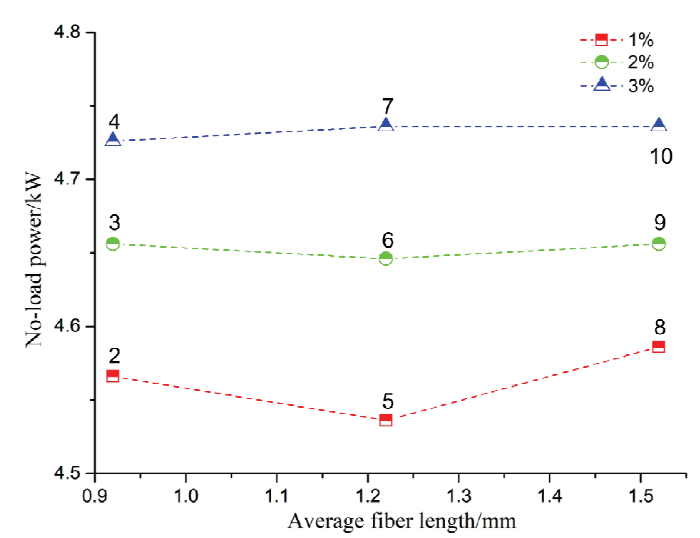

Fig. 8. Effect of average fiber length on the no-load power.

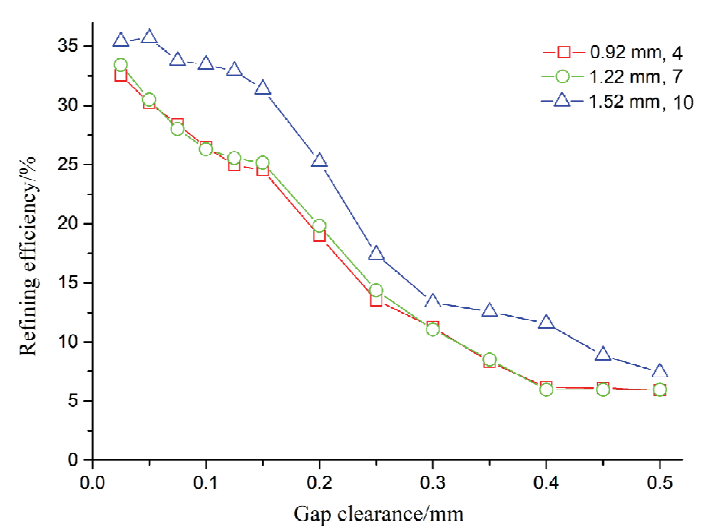

Fig. 9. Effect of average fiber length on the refining efficiency in LC refining (with pulp consistency of $3 \%)$. 
longer fiber length was refined. However, the increasing rate of refining efficiency influenced by the average fiber length is much lower than that of pulp consistency in the LC refining process. The effect of other fiber morphological properties on the power consumption and refining efficiency in LC refining should be further studied.

\section{CONCLUSION}

In this paper, the effects of pulp consistency and average fiber length on the power consumption and refining efficiency of the low consistency refining process were studied, and the main conclusions are as follows.

1. The power consumption of LC refining is closely related to the gap clearance. And the change of power consumption can be divided into three sections, constant power section, power reduction section, and power increase section, according to the gap clearance. The no-load power can be characterized by the power in the constant power section, and the power change in the reduction section is really small which can be ignored. Meanwhile, the characterization of the beginning of efficient refining can be expressed by the critical gap clearance.

2. The pulp consistency has a greater influence on power consumption and refining efficiency in the LC refining. The no-load power and the critical gap clearance gradually increase with the increase of the pulp consistency during the refining process. And the adjustable domain of the impact performance can be properly improved by reasonably determining the pulp consistency, which is the benefit to the reduction of energy consumption in LC refining.

3. Compared with the pulp consistency, there is a sight effect of the average fiber length on the power consumption and refining efficiency in LC refining. And the effect of it on the no-load power of the refin- ing can be neglected, while the adjustable domain of the impact performance of the LC refining process and refining efficiency would be larger when the long fibers were refined.

\section{ACKNOWLEDGMENT}

The authors gratefully acknowledge the funding by the National Natural Science Foundation of China, Grant No. 50745048, Shaanxi Provincial Key Research and Development Project, Grant No. 2020 GY-105, and 2020 GY-174.

\section{REFERENCES}

Banks, W.A. 1967. Design considerations and engineering characteristics of disc refiners, Paper Technology and Industry 8(4): 363-369.

Bordin, R., Roux, J.C., Bloch, J.F. 2008. No-load power evolution during low consistency pulp beating, Nordic Pulp and Paper Research Journal 23(1): 34-38.

Gharehkhania, S.,Sadeghinezhada, E., Kazi, S.N., Yarmand, H., Badarudin, A., Safaei, M.R., Zubir, M.N. M. 2015. Basic effects of pulp refining on fiber properties-a review, Carbohydrate Polymers 115: 785-803.

Guo, X.Y., Dong, J.X., Liu, H., Duan, C.W, Yang, R. F., Qi, K. 2020. Effect of combined refining plates with different bar angles on paper properties during mixed pulp refining. Journal of the Korean Wood Science and Technology 48(5): 581-590.

He, B.H. 2010. Refining, in: Papermaking principle and engineering, H. Beihai (ed.), China Light Industry Press, Beijing, China, pp. 32-34.

Jorge, E.R.B., Martinez, D.M., Olson, J.A. 2019. Power-gap relationship in low consistency refining, Nordic Pulp \& Paper Research Journal 34(1): 36-45. Lundin, T., Wurlitzer, F., Park, S.W., Fardim, P. 2009. 
Energy analysis in low consistency refining of softwood, O Papel 70(10): 41-60.

Lumiainen, J. 1990. New theory can improve practice, Pulp Paper International 32(8): 46.

Lumiainen, J. 1994. Is the lowest refining intensity the best in low consistency refining of hardwood pulps? in Tappi Press: Papermakers Conference, Atlanta, pp. 115-126.

Liu, H., Dong, J.X., Guo, X.Y., Wang, B., Duan, C.W, Qi, K., Kong, L.B. 2020. No-load power of disc refiner in low consistency refining. Journal of Korea TAPPI 6(2): 87-96.

Lundin, T. 2008. Tailoring pulp fibre properties in low consistency refining. Ph.D thesis, ABO Akademi University, Oulu, Sweden.

Luukkonen, A. 2011. Development of a methodology to optimize low consistency refining of mechanical pulp. Ph.D thesis, University of British Columbia,
Vancouver, Canada.

Roux, J.C., Bloch, J.F., Bordin, R., Nortier, P. 2009. The net normal force per crossing point: A unified concept for the low consistency refining of pulp suspensions. In Advances in Pulp and Paper Research, Oxford, pp. 51-83.

Rajabi Nasab, N., Olson, J.A., Heymer, J., Martinez, D.M. 2013. Understanding of no-load power in low consistency refiners. Canadian Journal of Chemical Engineering 92(3): 524-535.

Ragnar, B. 1970. Report:theory and operation of modern disc refiners, Black Clawson, pp. 4-5.

Roux, J.C. 2001. Stock Preparation. Part 1: Pulp Treatment Process, 12th Fundamental Research Symposium, Oxford, UK, pp. 17-21.

Wultsch, F., Flucher W. 1958. Der Escher-WyssKleinrefiner als Standard Prüfgerät fûr moderne Stoffaufbereitungsanlagen, Das Papier 12(13): 334. 